\title{
THE TECHNIQUE AND COMPLICATIONS OF PULMONARY VALVOTOMY WITH SPECIAL REFERENCE TO THE TRANSARTERIAL APPROACH
}

\author{
BY
}

\author{
FREDERIK THERKELSEN \\ From the University Clinic, Copenhagen, and the Rigshospitalet, Surgical Departments $D$ and $R$
}

(RECEIVED FOR PUbLICATION JANUARY 4, 1955)

Valvotomy for pulmonary stenosis has been used in our departments since August, 1950. Cases operated on by Brock's method and certain cases operated on by the transarterial route through a special clamp first described by Søndergaard (1953) have been dealt with in a previous communication (Therkelsen, 1952).

The present paper describes our latest observations with special reference to our experience with a method of valvotomy performed directly through the pulmonary artery.

\section{Diagnosis}

Pre-operatively the diagnosis was assessed in the majority of cases by cardiac catheterization, and in some angiocardiography was also performed.

\section{INDICATIONS}

Pure Pulmonary Stenosis and Pulmonary Stenosis Associated with Atrial Septal DEFECT.-This is an indication provided that the stenosis is of the valvular type. Most of the patients were gravely disabled, having dyspnoea on exertion and at rest. Our series therefore consists mainly of patients with severe symptoms, though in view of present knowledge regarding the ultimate prognosis (Brock and Campbell, 1950) it would seem justified to operate prophylactically. This view, however, presupposes a low operative mortality.

Fallot's Tetralogy.-Operation is indicated provided the stenosis is valvular. In the past we always treated these patients with a Blalock shunt operation when possible, but in recent years we have performed a number of valvotomies for the condition.

\section{Operative Technique}

A left-sided posterolateral incision is made, the fifth rib resected, and the pericardium opened. The cardiac catheterization findings are checked, and the stenosis diagnosed as being valvular or infundibular. This examination is supplemented by direct pressure measurements in the pulmonary artery and the right ventricle.

Two techniques have been used for valvotomy: (1) The transventricular approach as described by Brock, and (2) a transpulmonary approach.

The transpulmonary valvotomy has been performed in two ways.

The first method was described by Søndergaard in 1952, and consisted of an approach through a specially constructed " ring clamp."

We have used a simpler approach devised by Pettersson in 1953. By this method the pulmonary artery is entered through a very small incision situated between two half purse-string stay sutures (Fig. 1). It is important not to place the incision too close to the valves, as this makes the intro-

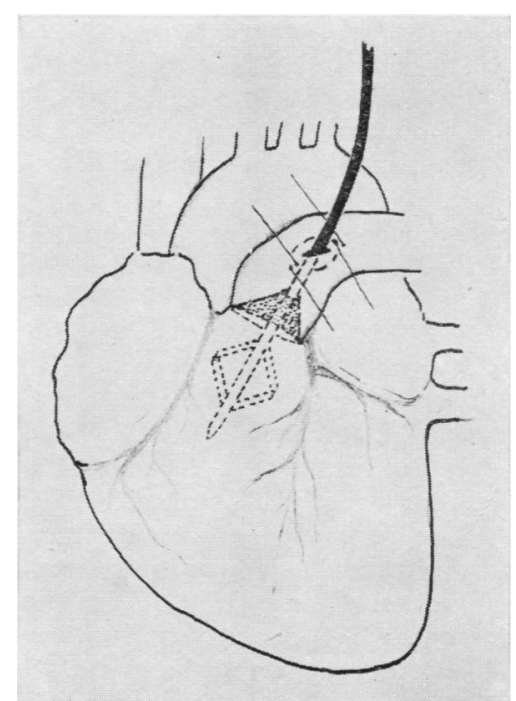

FiG. 1. - The " direct" pulmonary valvotomy performed with the
modified Potts-Rikers valvotome. 


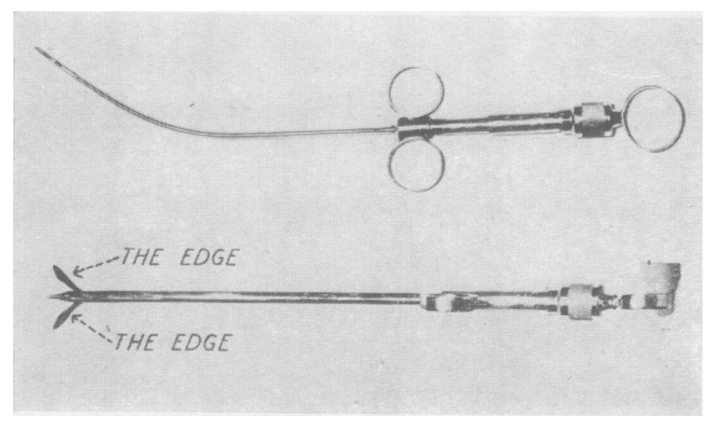

FIG. 2.-Our special knife for valvotomy.

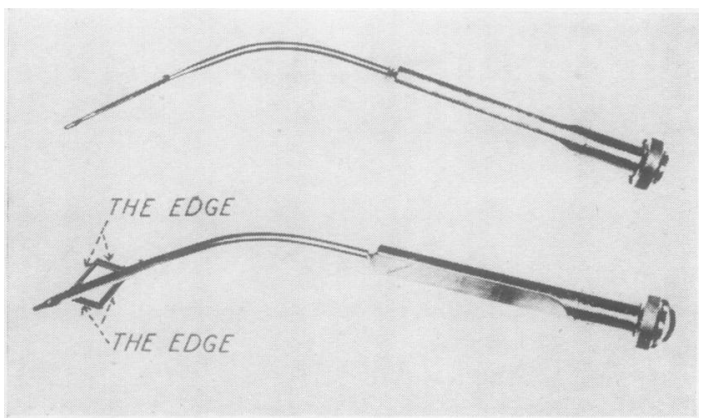

Fig. 3.-The Potts-Rikers valvotome (modified).

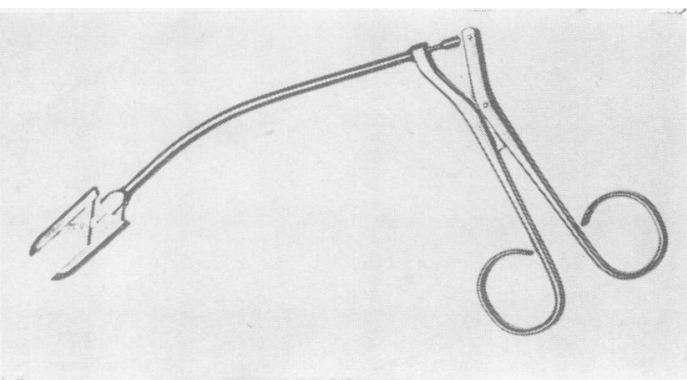

FIG. 4.-The dilator (Brock modified).

duction of the special dilator difficult. Until the incision is made and the tip of the instrument is introduced into the pulmonary artery, this segment of the artery is occluded from the blood stream by a Satinsky clamp, or, if it is small, by a Derra clamp. Then the clamp is released and the valvotome introduced through the stenosis, where it is unfolded to suit the size of the pulmonary ostium and finally pulled back through the stricture. If necessary as a further step a dilator is introduced to enlarge the incision made by the valvotome. The change of instruments is performed with a clamp partly occluding the pulmonary artery, and at the end the incision is closed with a continuous silk suture threaded on an atraumatic needle.
Blood loss during the procedure is usually slight, as a light pull on the stay sutures prevents leakage.

\section{INSTRUMENTS}

Only small, slender instruments have made it possible to use such a simple, direct method, and in our first cases we used a special knife which unfolded after introduction through the stenosis (Fig. 2). Further experience has shown, however, that the Potts-Rikers valvotome (also used by Pettersson) is more stable and safe. In our modification (Fig. 3) it is very easy to adjust the diameter of the cutting frame (from 5 to $25 \mathrm{~mm}$.). Two sizes of the valvotome are necessary if valvotomy is to be performed in all age groups.

When it is advisable to dilate the incision in the valves we use a modification of the dilator devised by Brock (Fig. 4).

\section{The Material}

In our surgical departments between August, 1950, and October 20,1954, valvotomy has been carried out in 31 cases of pure pulmonary stenosis and pulmonary stenosis associated with an atrial septal defect, and in 32 cases of Fallot's tetralogy.

In cases with Fallot's tetralogy we always open the pericardium, and if the stenosis is valvular and the size of the pulmonary ostium satisfactory, a valvotomy is performed. In other cases a Blalock's operation is performed. For these the incision in the pericardium is continued along the left pulmonary artery so that it is easily isolated. When the subclavian artery is too short or narrow for an anastomosis we do Barrett's operation, and, if necessary, at a further operation some months later attempt a Blalock's operation on the other side.

Up to October 20,1954, we have performed 139 operations.

Blalock's operation . . . . 111 (5 deaths) Exploratory thoracotomy +

Barrett's operation

28 (4 deaths)

The number of patients treated with valvotomy is 63 (Figs. 5-6), of whom one had had a previous Barrett's operation and two a previous unsuccessful Blalock's operation. Of these, 54 patients had a valvular stenosis, seven had a short and high infundibular stenosis, and two a long infundibular stenosis.

One of the two patients who had been submitted to a Blalock's operation because his disease was misdiagnosed as Fallot's tetralogy developed cardiac insufficiency with ascites and peripheral oedema after the operation. Four years later he 
was re-operated upon and a valvotomy was carried out for typical valvular stenosis. Nine months after this his condition had changed miraculously, both ascites and oedema having disappeared, and his range of physical activity being practically normal. This case demonstrates the danger of a shunt operation in pulmonary stenosis (Therkelsen, 1953).

\section{Sex and Age Distribution}

Among our patients there were 33 men and 30 women. The age of the patients ranged from 8 months to 48 years. The age distribution is shown in Figs. 5 and 6 with the relationship between the number of valvotomies for pulmonary stenosis or Fallot's tetralogy in the different age groups. In the younger age groups valvotomy for Fallot's tetralogy has been performed more frequently than valvotomy for pulmonary stenosis. This

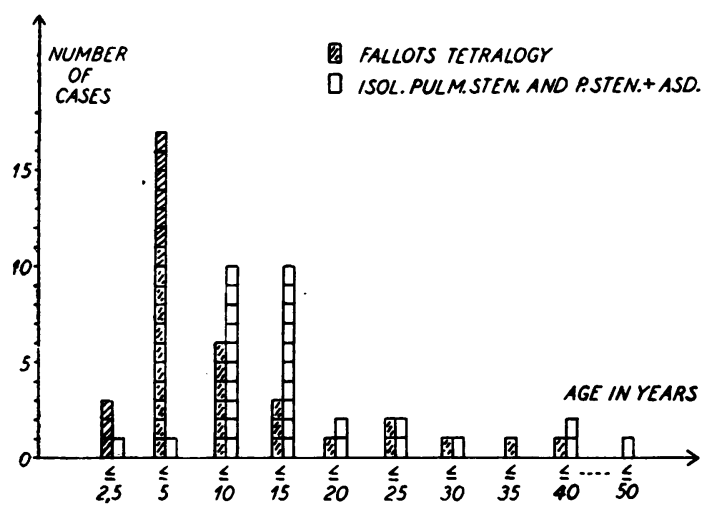

FIG. 5.-Age distribution of the operated cases of Fallot's tetralogy and isolated pulmonary stenosis and pulmonary stenosis associated with atrial septal defect.

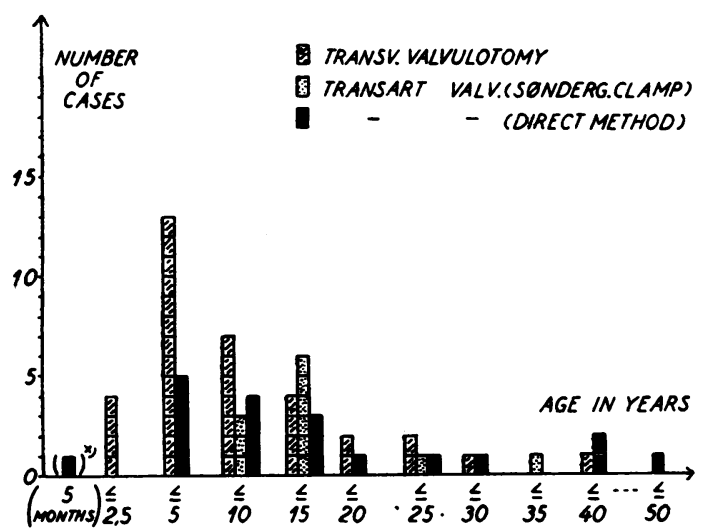

FIG. 6.-Age distribution of the cases operated on by the different methods. * A 5-month-old girl with pulmonary stenosis and stenosis of the tricusps treated by "direct" transarterial valvotomy. fact underlines the severity of symptoms from Fallot's tetralogy even at an early age by comparison with those from pulmonary stenosis in which the indication for operation has been prophylactic in some cases.

\section{Operative and Post-operative Complications}

As seen from Table I, most complications have occurred in the cases of Fallot's tetralogy. Four patients have died.

TABLE I

COMPLICATIONS IN 63 PULMONARY VALVOTOMIES

\begin{tabular}{|c|c|c|c|c|c|}
\hline & Approach & స్ & Complications & $\underset{\tilde{H}}{\overrightarrow{0}}$ & ڤ̆ \\
\hline \multirow[t]{2}{*}{$\begin{array}{l}\text { Fallot's } \\
\text { tetralogy } \\
32 \text { cases }\end{array}$} & Transventricular & $23^{1}$ & $\begin{array}{l}\text { Valvotomy failed } \\
\text { Transient bad } \\
\text { heart action } \\
\text { Cerebral anoxia } \\
\text { Cerebral throm- } \\
\text { bosis }\end{array}$ & $\begin{array}{l}4 \\
2 \\
1 \\
2\end{array}$ & $2^{5}$ \\
\hline & $\begin{array}{l}\text { Transarterial } \\
\text { through a } \\
\text { special clamp } \\
\text { Transarterial } \\
\text { " direct" }\end{array}$ & $\begin{array}{l}2^{2} \\
7\end{array}$ & $\begin{array}{l}\text { Valvotomy failed } \\
\text { Cardiac arrest } \\
\text { Transient bad } \\
\text { heart action }\end{array}$ & $\begin{array}{l}1 \\
1\end{array}$ & $1^{6}$ \\
\hline \multirow{3}{*}{$\begin{array}{l}\text { Isol. pulmon- } \\
\text { ary steno- } \\
\text { sis and } \\
\text { pulmonary } \\
\text { stenosis } \\
\text { and atrial } \\
\text { septal } \\
\text { defect } \\
31 \text { cases }\end{array}$} & Transventricular & $11^{3}$ & Pneumonia & 1 & $1^{7}$ \\
\hline & $\begin{array}{l}\text { Transarterial } \\
\text { through a } \\
\text { special clamp } \\
\text { Transarterial } \\
\text { " direct" }\end{array}$ & $\begin{array}{r}9^{4} \\
11\end{array}$ & $\begin{array}{l}\text { Transient bad } \\
\text { heart action } \\
\text { No complications }\end{array}$ & 1 & \\
\hline & Total & 63 & & & 4 \\
\hline
\end{tabular}

${ }^{1}$ Four patients had an infundibular stenosis. ${ }^{2}$ Two patients had an infundibular stenosis.
4 Two patients had an infundibular stenosis. 5 The cause of death was bleeding and cardiac arrest. 35 -year-old man, who died one month after the operation. Necropsy showed endocarditis. 7 16year-old girl with pulmonary stenosis and atrial septal defect and constr. pericarditis. At the same operation we performed pericardiectomy and pulmonary valvotomy without operative complications. She died 48 hours post-operatively. The necropsy showed an atelectasis with pneumonia.

\section{Discussion}

The transarterial approach appears superior to the transventricular for the following reasons: (1) Neither the myocardium nor the coronary vessels can be injured. (2) There is almost unlimited time available for introducing the various instruments. Bleeding is usually simple to control, since in cases of both pulmonary stenosis and Fallot's tetralogy the pressure in the pulmonary artery is very low. In very small children, however, even a small loss of blood may affect the cardiac function, and in such cases unnecessary manipulations must be avoided. (3) In cases of Fallot's tetralogy the overriding aorta very frequently makes the transventricular approach diffi- 
cult. Most cases of failed valvotomy by this route have been due to the valvotome entering the aorta rather than the pulmonary artery, but only one was a failure when the approach was made through the pulmonary artery.

The pulmonary artery is very often small in cases of Fallot's tetralogy and in young children with isolated pulmonary stenosis, so that placing of Søndergaard's ring clamp may be impossible, since its use presupposes a fairly wide vessel. This difficulty is accentuated if it is desired to clamp off part of the vessel before putting it in place. In fact we have introduced the clamp without this precaution, but such a procedure is difficult and dangerous and not to be recommended. For these reasons Søndergaard's method has only been used in patients over 5 years of age.

The "direct" transarterial method is easy and safe to perform when it is possible to clamp off a part of the pulmonary artery with a small Derra clamp and to place a purse-string suture on the pulmonary artery at the point where the valvotome is to be introduced.

Our views on the methods of valvotomy may be illustrated by a study of the number of cases operated on in our departments by the different techniques from August, 1950 (when we first adopted valvotomy), up to the present date. During the first 15 months we only used the transventricular approach. For one and a half years from December, 1951, we performed both transventricular (10 cases) and transarterial valvotomies with the Søndergaard clamp (11 cases). Since November, 1953, when we adopted the "direct " transarterial route, we have only performed transventricular valvotomy in three out of 21 cases, and in the same period we have done no cases by the Søndergaard method.

The following case illustrates the possibilities of the "direct" transpulmonary method.

\section{CASE REPORT}

Valvotomy was performed on a 5-month-old girl. The child was in poor condition with severe dyspnoea at rest, and the diagnosis was of Fallot's tetralogy. After opening the pericardium, but before valvotomy, the heart action became poor, but improved with massage and the intraventricular injection of adrenaline. However, experience with two other cases suggested that only valvotomy would permanently improve the condition of the heart by increasing blood flow through the pulmonary artery, so this was carried out. It was easily done and the cutting diameter of the valvotome was $10 \mathrm{~mm}$. The heart beat improved at once, but the child died 15 hours post-operatively. At necropsy, in addition to the divided stenotic pulmonary valves, there was stenosis of the tricuspid valve and considerable hypertrophy of the right ventricle.

In collaboration with the medical and paediatric departments an analysis is being made of the pressure measurements at cardiac catheterization and the direct measurements during the operation, together with a clinical follow-up of the patients. In nearly all cases of pulmonary stenosis, which have been re-examined and in which post-operative intracardiac pressure measurements have been done, the pressure in the right ventricle has decreased, but in no case to the normal level. Therefore consideration must be given to the view that better results may follow cutting of the valves under direct vision, and particularly so when the stenosis is infundibular. Such operations performed by Swan and Brock under hypothermia have already given promising results.

\section{SUMMARY}

Sixty-three cases of pulmonary valvotomy with four deaths are described, with the indications for, and technique of, operation. Eighteen valvotomies have been performed by a "direct" transarterial approach, which is considered the simplest and safest procedure available.

\section{REFERENCES}

Brock, R. C., and Campbell, M. (1950). Brit. Hea $t$ J., 12, 337. Pettersson, G. (1953). Personal communication.

Søndergaard, T. (1952). Acta chir. scand., 104, 362.

Therkelsen, F. (1952). Ibid., 104, 353.

(1953). Ibid., 166, 257. 